${ }^{1}$ Oddział Kliniczny Chorób Wewnętrznych, Diabetologii i Schorzeń Kardiometabolicznych, Śląskie Centrum Chorób Serca w Zabrzu,

${ }^{2}$ Merck Sp. z o.o., Warszawa

${ }^{3}$ Merck KGaA, Darmstadt, Niemcy

\title{
Patient adherence to and tolerability of treatment with metformin extended-release formulation in patients with type 2 diabetes. GLUCOMP study
}

\section{ABSTRACT}

Introduction. Appropriate treatment of diabetes requires regular intake of recommended drugs. Multifactorial therapy, which necessitates the concomitant use of many medications, may decrease patient adherence. The purpose of the study was to assess type 2 diabetic patients' adherence to and tolerability of metformin extended-release formulation in the outpatient setting. Materials and methods. This non-interventional study was conducted in a group of $\mathbf{4 7 3 7}$ patients [including 2468 (52\%) women] with mean age of $60.6 \pm 9.4$ years, diabetes duration of $5.6 \pm 4.4$ years, duration of treatment with metformin extended release formulation of $8.3 \pm 12$ months at an average dose of $1667 \pm 350 \mathrm{mg}$. The study enrolled patients aged over 18 years with type 2 diabetes if they were treated with metformin extended-release formulation at a dose of 1500-2000 mg for less than 1 year prior to the study enrollment. The exclusion criteria included: pregnancy, breast-feeding and any contraindications for metformin treatment.

Address for correspondence:

prof. dr hab. n. med. Krzysztof Strojek

Oddział Kliniczny Chorób Wewnętrznych, Diabetologii i Schorzeń

Kardiometabolicznych Śląskie Centrum Chorób Serca

ul. M. Curie-Skłodowskiej 9, 41-800 Zabrze

Phone: +48 (32) 3733864

Fax: +48 (32) 2784334

e-mail: kstrojek@sum.edu.pl

Clinical Diabetology 2016, 5, 1, 15-21

DOI: $10.5603 /$ DK.2016.0003

Translation: dr med. Jędrzej Toczko,

dr hab. med. Anna Korzon-Burakowska

Received: 04.12.2015

Accepted: 28.01.2016
Treatment adherence was assessed by a tablet count (percentage of prescribed tablets taken) and using the Morisky-Green scale. Treatment adherence was defined as follows: excellent patient adherence if $>90 \%$ of prescribed tablets were taken; good: $76-90 \%$; moderate: $51-75 \%$; poor: $\leq \mathbf{5 0} \%$. Treatment tolerability was also evaluated based on the medical history focused on gastrointestinal symptoms, as well as patient preference for using specific types of metformin. Other patient data, clinical data and laboratory test results were recorded at the beginning of the study and after 3 months.

Results. After 3 months of treatment with metformin extended release formulation $96 \%$ of study subjects demonstrated excellent or good adherence. Treatment adherence was significantly lower with 2 or 3 concomitant medications as compared to one $(p<0.001)$. Adverse events occurred in 715 patients (15\% out of 4758 patients undergoing safety analysis). The occurrence of adverse events significantly decreased treatment adherence ( $p<0.001$ ). Approximately $90 \%$ of patients declared they had preferred the use of metformin extended-release formulation.

Conclusions. Metformin extended-release formulation is a suitable, well tolerated therapeutic option which helps to obtain good patient cooperation based on good adherence. (Clin Diabet 2016; 5, 1: 15-21)

Key words: type 2 diabetes, metformin extended-release formulation, treatment, adherence, adverse events 


\section{Introduction}

Epidemiological data shows increasing incidence of diabetes [1]. It is primarily an increase in type 2 diabetes patients numbers [2]. The main concern in diabethology is the occurrence of late complications, being the cause of premature death, disability and decline in quality of life [3]. Up-to-date diabetes treatment aimed at preventing complications includes the so called 'multifactorial therapy', consisting of normalization of glycaemia, lipemia and arterial blood pressure [4]. A treatment which provides reaching optimal blood glucose levels is one of the key elements of an effective therapy [5]. The typical progressive course of type 2 diabetes determines the need for gradual intensification of treatment, raging from diet and oral medicaments in mono- and polytherapy, to insulin therapy at the other end of the spectrum $[6,7]$. Metformin plays a prominent part amongst oral antiglycemic medicaments, showing not only antiglycemic effects, but also additional cardioprotective properties which have been proven by prospective studies $[8,9]$. In accordance with type 2 diabetes therapeutic guidelines for treating hyperglycaemia, metformin should be used at every stage of the treatment, provided that no contradictions or intolerance symptoms occur $[6,7]$. Metformin extended-release (Glucophage ${ }^{\circledR} \mathrm{XR}$ ) formulation is a recently introduced drug form which, through adequate tablet construction, enables administering once a day [10]. Using this form of the drug is related to lower incidence of adverse events [11].

Level of adherence and regular drug intake are vital aspects of an effective antidiabetic therapy [12, 13].

The purpose of the study was to asses:

- adherence to therapeutic guidance;

- tolerability (incidence of adverse events);

- patients preference, concerning the metformin extended-release formulation use compared with standard metformin form in patients with type 2 diabetes treated with metformin extended-release formulation (Glucophage ${ }^{\circledR} \mathrm{XR}$ ) in the outpatient setting.

\section{Materials and methods}

This non-interventional study was conducted in a group of 4737 patients, whose data was collected in 601 study centers.

Study inclusion criteria:

- extended-release metformin (Glucophage ${ }^{\circledR}$ XR) treatment no longer than a year prior study inclusion;

- age of 18 or older;

- $\mathrm{HbA}_{1 \mathrm{c}}$ blood test performed up to one year prior inclusion.
Study exclusion criteria:

- any contraindications for metformin treatment;

- pregnancy or breastfeeding;

- no effective contraceptive therapy if of childbearing age.

The conducted study consisted of two visits separated with 3 months, with data collected using a Case Report Form (CRF):

- general information - age, sex, BMI, duration of diabetes, duration of metformin extended-release formulation treatment;

- medical history of diabetes complications and comorbidities such as arterial hypertension and dyslipidemia. The investigator ascertained arterial hypertension based on anamnesis and a routine blood pressure check during the first visit (blood pressure equal or greater than $140 / 90 \mathrm{~mm} \mathrm{Hg}$ or antihypertensive therapy). The investigator ascertained dyslipidemia based on anamnesis (incorrect blood lipid values or antilipemic therapy);

- information on physical activity and education level. Type 2 diabetes education level was assessed by the investigator based on anamnesis data such as: type of received education ( self-education, education conducted by a nurse, a diabetic educator or a doctor), weekly hours of education $(1-2,3-4,5-6,>6)$, how many times a week (daily, 2-3 times a week, once a week or less) and in a subjective, 4-level scale: unsatisfactory, sufficient, good, excellent;

- current antiglycemic treatment;

- glycaemia control (fasting glycaemia, postprandial glycaemia, $\mathrm{HbA}_{1 \mathrm{c}}$ );

- metformin intolerance symptoms;

- treatment adherence, by numbers of prescribed and taken tablets of metformin extended-release formulation.

The primary endpoint of the study was treatment adherence during metformin extended-release formulation therapy. Treatment adherence was assessed by a tablet count (percentage of prescribed tablets taken). Treatment adherence was defined as follows: excellent adherence if $>90 \%$ of prescribed tablets were taken, good: $76-90 \%$, moderate: $51-75 \%$, poor: $\leq 50 \%$.

Treatment adherence was also assessed using the Morisky-Green scale [14], grading it as low, medium or high. These categories were assigned based on a score, resulting from a 4 step questionnaire (yes -1 point, no -0 points):

- Do you ever forget to take your medicine?

- Are you careless at times about taking your medicine?

- When you feel better do you sometimes stop taking your medicine? 
- Sometimes if you feel worse when you take the medicine, do you stop taking it?

Patients assigned to high treatment adherence group answered negatively on all of the questions (0 points); these assigned to medium treatment adherence group received 1-2 points, and to low treatment adherence group: 3-4 points.

The secondary endpoint of the study was an assessment of patients' preference concerning extended-release metformin compared with retrospective data describing standard drug form usage and an evaluation of tolerance of currently used metformin extended-release formulation.

Only authorized personnel had access to identification enabling information, if verification was necessary. Legal regulations related to personal data and privacy protection were complied with while gathering, forwarding, processing and storing patients' data.

A descriptive statistical analysis was performed. Mean values, standard deviations and quartiles were calculated. Correlation analysis and $\chi^{2}$ test were performed for the primary endpoint with following values: prescribed tablets count, taken tablets count, physical activity, gastrointestinal intolerance, diabetes duration and antidiabetic treatment duration.

\section{Results}

The study enrolled 4737 patients [including 2468 (52\%) women] with mean age of $60.6 \pm 9.4$ years, diabetes duration of $5.6 \pm 4.4$ years, duration of treatment with metformin extended-release formulation of $8.3 \pm$ \pm 12 months at an average dose of $1667 \pm 350 \mathrm{mg}$. Average BMI of patients enrolled in the study was $30.5 \pm$ \pm 4 .3. The profile of the study group is presented in Table 1.

Amongst enrolled patients $50 \%$ had coexisting macroangiopathy, microangiopathy was present in $33 \%$, arterial hypertension in $88 \%$; $83 \%$ had dyslipidemia. $15 \%$ of the group were active smokers, $26 \%$ former smokers. In the hypertensive patients group $53 \%$ received 1 hypotensive drug as treatment, 5\% received two drugs, $0,2 \%-3$ or more drugs.

Table 2 presents treatment adherence concerning diabetes treated with metformin extended-release formulation based on a prescribed/taken tablets ratio. An overwhelming majority of patients presented excellent or good treatment adherence (96\%). This table also displays treatment adherence concerning diabetes treated with extended-release metformin, estimated with the Morisky-Green scale. Results are similar to those obtained by the prescribed/taken tablet ratio method, showing over $90 \%$ of excellent or good treatment adherence.
Table 1. Demographics

\begin{tabular}{|c|c|c|}
\hline & & $n=4737$ \\
\hline \multirow{2}{*}{ Age (years) } & Mean (SD) & $60.6(9.4)$ \\
\hline & Min., max. & $21 ; 98$ \\
\hline \multirow{2}{*}{ Sex } & Female & $2468(52.1 \%)$ \\
\hline & Male & $2269(47.9 \%)$ \\
\hline \multirow{2}{*}{ Body mass index $\left[\mathrm{kg} / \mathrm{m}^{2}\right]$} & Mean (SD) & $30.5(4.3)$ \\
\hline & Min., max. & $17.3 ; 67.0$ \\
\hline \multirow{3}{*}{ Nicotine use } & Smoker & $693(14.6 \%)$ \\
\hline & Ex-smoker & $1240(26.2 \%)$ \\
\hline & Non-smoker & $2804(59.2 \%)$ \\
\hline \multirow{4}{*}{ Education level } & Excellent & $346(7.3 \%)$ \\
\hline & Good & $1952(41.2 \%)$ \\
\hline & Sufficient & $2029(42.8 \%)$ \\
\hline & Unsatisfactory & $410(8.7 \%)$ \\
\hline Physical activity & $>$ once a week & $2237(47.2 \%)$ \\
\hline Macroangiopathy & & $2378(50.2 \%)$ \\
\hline Microangiopathy & & $1559(32.9 \%)$ \\
\hline Arterial hypertension & $>140 / 90 \mathrm{~mm} \mathrm{Hg}$ & $4165(87.9 \%)$ \\
\hline Dyslipidemia & & 3922 (82.8\%) \\
\hline \multirow[t]{2}{*}{ Fasting glycaemia [mg/dL] } & Mean (SD) & $122(24)$ \\
\hline & Min., max. & $60 ; 308$ \\
\hline Postpriandal glycaemia & Mean (SD) & $152(32)$ \\
\hline$[\mathrm{mg} / \mathrm{dL}]$ & Min., max. & $74 ; 488$ \\
\hline \multirow[t]{2}{*}{$\mathrm{HbA}_{1 \mathrm{c}}(\%)$} & Mean (SD) & $7.05(0.86)$ \\
\hline & Min., max. & $4.7 ; 13.8$ \\
\hline
\end{tabular}

SD - standard deviation

Table 2. Levels of treatment adherence concerning extended-release metformin based on a tablet count and Morisky-Green scale

\begin{tabular}{lcc}
\hline Treatment adherence & $\mathbf{n}$ & $\%$ \\
\hline Tablet count & & \\
Excellent & 4063 & 85.8 \\
Good & 505 & 10.7 \\
Moderate & 128 & 2.7 \\
Poor & 40 & 0.8 \\
Morisky-Green scale & & \\
High & 3705 & 78.2 \\
Medium & 895 & 18.9 \\
Low & 137 & 2.9 \\
\hline
\end{tabular}

Treatment adherence concerning diabetes treated with extended-release metformin was dependent on: the number of tablets prescribed, number of other concomitant medications taken (taking more than 2 drugs impaired treatment adherence), physical activity (patients with excellent treatment adherence reported 
being physically active more than once a week). Further analysis proved that lack of gastrointestinal adverse events resulted in an increase in treatment adherence, while longer diabetes and metformin treatment duration were correlated with lower treatment adherence.

Analysis of patients' preference regarding metformin extended-release formulation and conventional form showed that $90 \%$ of patients preferred extendedrelease form, $9 \%$ showed no preference at all and $1 \%$ preferred standard metformin form.

Table 3 shows incidence of adverse events during the observation period. Adverse events were noted in 715 patients (15\% of 4737 patients who were subject to safety analysis). Most frequent adverse events that occurred during the study were: nausea (261, 5.5\%), diarrhea $(259,5.4 \%)$ and abdominal pain $(233,4.9 \%)$.

Table 4 displays treatment adherence in relation to the amount of concomitant medicaments. Excellent treatment adherence assessed by metformin tablets used by the patient was observed in $87 \%$ of patients taking only 1 drug, $86 \%$ taking 2 drugs and $75 \%$ of patients taking 3 drugs ( $p<0,001$ ). Percentages patients of excellent treatment adherence assessed with the Morisky-Green scale were $83 \%, 75 \%$ and $65 \%$ accordingly $(p<0.001)$.
Table 5 presents treatment adherence in relation to observed gastrointestinal adverse events. A significant decrease in treatment adherence was observed when these effects occurred. High percentage of treatment adherence was ascertained in $87 \%$ of patients without gastrointestinal adverse events and $63 \%$ of patients with them while using the tablet count method, whereas Morisky-Green scale results were accordingly $80 \%$ vs. $54 \%$.

\section{Discussion}

Metformin is the drug of choice in pharmacological treatment of type 2 diabetes [15]. However, using standard metformin has a few restraints, such the need of taking it 2-3 times a day or very common gastrointestinal adverse events, namely nausea, vomiting, diarrhea, abdominal pain or appetite loss [16]. Treatment adherence is a vital issue especially in regard of chronic diseases, such as diabetes [17]. Extended-release metformin provides a chance of increasing treatment adherence and improve gastrointestinal tolerance of the drug.

This study demonstrates excellent treatment adherence related to metformin extended-release formulation (Glucophage ${ }^{\circledR} \mathrm{XR}$ ). Relatively good treatment adherence was also displayed by patients using other concomitant drugs and patients experiencing adverse events. Thera-

Table 3. Incidence of adverse events

\begin{tabular}{lcccc}
\hline & $\begin{array}{c}\text { Patients with at } \\
\text { least one adverse } \\
\text { events present }\end{array}$ & $\begin{array}{c}\text { \% of all adverse } \\
\text { events }\end{array}$ & $\begin{array}{c}\text { \% of patients with } \\
\text { adverse events }\end{array}$ & $\begin{array}{c}\text { \% all } \\
\text { patients }\end{array}$ \\
\cline { 2 - 5 } & & & $\mathbf{n}=\mathbf{7 1 5}$ & $\mathbf{n = 4 7 3 7}$ \\
\hline Nausea & 261 & 28.3 & 36.50 & 5.49 \\
Diarrhea & 259 & 28.1 & 36.22 & 5.47 \\
Abdominal pain & 233 & 25.2 & 32.59 & 4.92 \\
Apetite reduction & 121 & 13.1 & 16.92 & 2.55 \\
Bloating & 15 & 1.6 & 2.10 & 0.32 \\
Bomiting & 12 & 1.3 & 1.68 & 0.25 \\
Apetite loss & 8 & 0.9 & 1.12 & 0.17 \\
Gastrointestinal symptoms & 4 & 0.4 & 0.56 & 0.08 \\
Transient abdominal pains & 1 & 0.1 & 0.14 & 0.02 \\
Indigestion & 1 & 0.1 & 0.14 & 0.02 \\
Non-specific gastrointestinal symptoms & 1 & 0.1 & 0.14 & 0.02 \\
Heartburn & 1 & 0.1 & 0.14 & 0.02 \\
Unpleasant aftertaste & 1 & 0.1 & 0.14 & 0.02 \\
Unlpleasant taste & 1 & 0.1 & 0.14 & 0.02 \\
Constipation & 1 & 0.1 & 0.14 & 0.02 \\
Puritus & 1 & 0.1 & 0.14 & 0.02 \\
Vertigo & 1 & 0.1 & 0.14 & 0.02 \\
Viral infection & & 0.1 & 0.02 \\
\hline
\end{tabular}


Table 4. Levels of treatment adherence concerning extended-release metformin according to the number of drugs taken, based on a tablet count and Morisky-Green scale

\begin{tabular}{|c|c|c|c|c|c|}
\hline \multirow[t]{2}{*}{ Treatment adherence } & \multicolumn{3}{|c|}{ Number of drugs taken } & \multirow[t]{2}{*}{ Patients in total } & \multirow[t]{2}{*}{$\mathbf{P}\left(\chi^{2}\right)$} \\
\hline & 1 & 2 & $>2$ & & \\
\hline \multicolumn{6}{|l|}{ Tablet count } \\
\hline Patients in total & 1994 & 2499 & 243 & 4736 & $<0.001$ \\
\hline Poor & $16(0.8 \%)$ & $21(0.8 \%)$ & $3(1.2 \%)$ & $40(0.8 \%)$ & \\
\hline Moderate & $50(2.5 \%)$ & $56(2.2 \%)$ & $22(9.1 \%)$ & $128(2.7 \%)$ & \\
\hline Good & $191(9.6 \%)$ & $279(11.2 \%)$ & $35(14.4 \%)$ & $505(10.7 \%)$ & \\
\hline Excellent & $1737(87.1 \%)$ & $2143(85.8 \%)$ & $183(75.3 \%)$ & $4063(85.8 \%)$ & \\
\hline \multicolumn{6}{|l|}{ Morisky-Green scale } \\
\hline Patients in total & 1994 & 2500 & 243 & 4737 & $<0.001$ \\
\hline low & $48(2.4 \%)$ & $75(3.0 \%)$ & $14(5.8 \%)$ & $137(2.9 \%)$ & \\
\hline Moderate & $296(14.8 \%)$ & $529(21.2 \%)$ & $70(28.8 \%)$ & $895(18.9 \%)$ & \\
\hline High & 1650 (82.7\%) & $1896(75.8 \%)$ & 159 (65.4\%) & 3705 (78.2\%) & \\
\hline
\end{tabular}

Table 5. Levels of treatment adherence concerning extended-release metformin according to gastrointestinal adverse events, based on a tablet count and Morisky-Green scale

\begin{tabular}{|c|c|c|c|c|}
\hline \multirow[t]{2}{*}{ Treatment adherence } & \multicolumn{2}{|c|}{ Gastrointestinal adverse events } & \multirow[t]{2}{*}{ Patients in total } & \multirow[t]{2}{*}{$\mathbf{P}\left(\chi^{2}\right)$} \\
\hline & No & Yes & & \\
\hline \multicolumn{5}{|l|}{ Tablet count } \\
\hline Patients in total & 4046 & 690 & 4736 & $<0.001$ \\
\hline Poor & $24(0.6 \%)$ & $16(2.3 \%)$ & $40(0.8 \%)$ & \\
\hline Moderate & $84(2.1 \%)$ & $44(6.4 \%)$ & $128(2.7 \%)$ & \\
\hline Good & $376(9.3 \%)$ & $129(18.7 \%)$ & $505(10.7 \%)$ & \\
\hline Excellent & $3562(88 \%)$ & $501(72.6 \%)$ & $4063(85.8 \%)$ & \\
\hline \multicolumn{5}{|l|}{ Morisky-Green scale } \\
\hline Patients in total & 4046 & 691 & 4737 & $<0.001$ \\
\hline Low & $100(2.5 \%)$ & $37(5.4 \%)$ & $137(2.9 \%)$ & \\
\hline Moderate & 700 (17.3\%) & $195(28.2 \%)$ & $895(18.9 \%)$ & \\
\hline High & $3246(80.2 \%)$ & 459 (66.4\%) & 3705 (78.2\%) & \\
\hline
\end{tabular}

peutic guidance is in many cases followed correctly by the patients, reaching highest efficiency while using 1 or 2 drugs. A decrease in adherence occurring with coexisting adverse events indicates the need for adverse events monitoring throughout whole metformin treatment.

Presented study was conducted in 601 randomly chosen centers in Poland amongst 4737 patients treated with extended-release metformin. Given the randomness of center enrollment and the fact that patients where successively included into the study during control visits, it may be assumed that the study is representative of the metformin treated patient population. Structurally, the study consisted of two visits: initial visit, when general information was collected concerning patients profile, treatment, metabolic control or adverse events occurrence. Analysis was performed with data acquired during the final visit after 3 months of observation, assumption being that reliable results involving treatment adherence and calculated from prescribed/taken tablet ratio can only be ascertained within a defined timeline. The 3 months observation period enabled capturing all key stages of correct treatment adherence, starting with buying the prescribed drug, then beginning the treatment, up to its continuation after the whole pack had been taken.

There are different ways of assessing treatment adherence [18]. This study was conducted using a dual method. Firstly, it was calculated by prescribed and taken tablet count during a 3 month observation period, also referred to as the time between the first and the last visit. However, this approach may be a source of inaccuracies, as it is difficult to estimate the tablet 
count in everyday practice. For this reason, the results were validated with the Morisky-Green scale [14]. Questions included in it do not involve a timeline; therefore the patients' answers may have been related not only to the analyzed period, but to the whole treatment of diabetes, as well as to all taken medicaments instead of only the investigated drug. In authors' opinion, using two assessment methods simultaneously removes the inaccuracies and minimizes the risk of assessment error happening while using one method alone. It is important to highlight the fact that both methods indicated a high percentage of treatment adherence.

Some studies show that the level of treatment adherence correlates negatively with the number of tablets taken [19]. In the presented study we analyzed this parameter in relation to metformin , prescribed to be taken daily. However, mean dose of extended-release metformin taken by patients amounted to $1667 \mathrm{mg}$ a day, which suggests that the vast majority of patients had to take more than one tablet. The results obtained indicate that high level of treatment adherence remained in a meaningful negative correlation with the amount of tablets taken, although it must be noted that even with greater tablet numbers, it remained high (Tab. 4.) This demonstrates the need to emphasize reduction of tablet numbers, which can be achieved by i.e. using extended-release medications formulation.

Molsa et al. study analyzed treatment adherence in diabetic patients in the outpatient setting, based on the Morisky-Green scale [19]. The results shown a much higher adherence level amongst type 1 diabetes patients compared to type 2 diabetes patient. Amongst type 2 diabetes patients, in a population similar to presented study, no correlation was found between treatment adherence and body mass, diabetes duration or metabolic control. It is worth mentioning that Molsa et al. study categorized only $28 \%$ of patients as presenting high level treatment adherence. Higher percentages in the presented study seem to emerge from the fact that treatment adherence was only assessed concerning one medicament, not diabetes treatment as a whole.

Analysis of adverse events occurrence is a vital part of therapy effectiveness assessment. Literature data indicates that adverse events, mainly gastrointestinal, occur in $20-30 \%$ of patients treated with standard metformin and are dose dependant; however only 3-7\% of patients withdrew the treatment [20]. In regard of metformin extended-release formulation, the adverse event incidence did not exceed $20 \%$, while the proportion of patients interrupting the treatment oscillated around $2 \%$ [21]. In the presented study the incidence of adverse events was distinctly lower. This resulted from the observational study methodology and including patients permanently treated with extended-release metformin medications, which allowed pre-selection and exclusion of patients who were forced to withdraw treatment because of the adverse events. This brings the conclusion that adverse events reported by patients were mild enough to continue the treatment. While interpreting the use of the drug in patients who present adverse events, it must be noted that sometimes these effects occur later in time and patient may not associate it with the drug taken. This interference was demonstrated only by using patient observation form (CRF) containing detailed questions. However, the study results regarding treatment adherence indicate that presence of adverse events has a negative impact on it (Tab. 5). It must be noted that patients who experienced adverse effects still maintained a relatively high level of treatment adherence, which on the other hand points to a need of performing a more detailed anamnesis focused on adverse events at every visit, even in long term treatment, and possible treatment correction.

\section{Conclusions}

In conclusion, the study results indicate that metformin extended-release formulation is a good therapeutic option for acquiring patient compliance with high level of treatment adherence.

\section{Acknowledgements}

Authors would like to thank all the investigators taking part in the GLUCOMP Study.

\section{Conflict of interest}

The study was funded by Merck sp. z o.o.

Krzysztof Strojek received remunerations for lectures, publications and studies from: Abbott, AstraZaneca, Bayer, Berlin-Chemie, Boehringer Ingelheim, Eli Lilly, Merck, Novartis, Novo Nordisk, Polfa Tarchomin, Sanofi Aventis, Servier.

Anna Kurzeja is an employee for Merck Sp. z o.o., an angecy of Merck KGaA, Darmstadt, Germany.

Ulrike Gottwald-Hostalek is an employee for Merck KGaA, Darmstadt Germany.

\section{REFERENCES}

1. IDF Diabetes Atlas. Sixth edition http://wwww.idf.org/diabetesatlas.

2. Geiss LS, Wang J, Cheng IJ et al. Prevalence and Incidence Trends for Diagnosed Diabetes Among Adults Aged 20 to 79 years, United States, 1980-2012. JAMA 2014; 312: 1218-1226.

3. Zimmett $P$, Alberti KGMM, Shaw J. Global and societal implications of the diabetes epidemic. Nature 2001; 414: 782-778.

4. Gæde,P, Lund-Andersen $H$, Parving $H H$, Pedersen O. Effect of a multifactorial interventionon mortality in type 2 diabetes. N Engl J Med 2008; 358: 580-591. 
5. Stratton IM, Adler Al, Neil HA et al. Association of glycaemia with macrovascular and microvascular complications of type 2 diabetes (UKPDS 35): prospective observational study. BMJ 2000; 321: 405-412.

6. Zalecenia kliniczne dotyczące postępowania u chorych na cukrzycę 2010. Stanowisko Polskiego Towarzystwa Diabetologicznego. Diabetologia Kliniczna 2014; 3 (Suppl A).

7. Management of hyperglycaemia in type 2 diabetes: a patientcentered approach. Position statement of the American Diabetes Association (ADA) and the European Association for the Study of Diabetes (EASD). Diabetes Care 2012; 35: 1364-1379.

8. UK Prospective Diabetes Study (UKPDS) Group. Effect of intensive blood glucose control with metformin on complications in overweight patients with type 2 diabetes (UKPDS 34). Lancet 1998; 352: 854-865.

9. Kooy A, de Jager J, Lehert P et al. Long-term effects of metformin on metabolism and microvascular and macrovascular disease in patients with type 2 diabetes mellitus. Arch Intern Med 2009; 169: 616-625.

10. Timmins P, Donahue S, Meeker J, Marathe P. Steady-state pharmacokinetics of a novel extended-release metformin formulation. Clin Pharmacokinet 2005; 44: 721-729.

11. Blonde L, Dailey GE, Jabbour SA et al. Gastrointestinal tolerability of extended-release metformin tablets compared to immediate-release metformin tablets: results of a retrospective cohort study. Curr Med Res Opin 2004; 20: 565-572.

12. Cramer JA. A systematic review adherence with medications for diabetes. Diabetes Care 2004; 27: 1218-1224.
13. Donnan PT, MacDonald TM, Morris AD. Adherence to prescribed oral hypoglycaemic medication in a population of patients with type 2 diabetes: a retrospective cohort study. Diabet Med 2002; 19: 279-284.

14. Morisky DE, Green LW, Levine DM. Concurrent and predictive validity of a self- reported measure of medication adherence. Medical Care 1986; 24: 67-74.

15. Zalecenia kliniczne dotyczące postępowania u chorych na cukrzycę 2015. Stanowisko Polskiego Towarzystwa Diabetologicznego. Diabetologia Kliniczna 2015; 4 (Suppl A).

16. Charakterystyka Produktu Leczniczego Glucophage tabletki powlekane, http://www.leki.urpl.gov.pl/files/Glucophage_ tablpowl_850mg.pdf.

17. Cramer JA. A systematic review of adherence with medications for diabetes. Diabetes Care 2004; 27: 1218-1224.

18. Melikian C, White TJ, Vanderplas A et al. Adherence to oral antidiabetic therapy in a managed care organization: a comparison of monotherapy, combination therapy and fixed-dose combination therapy. Clin Ther 2002; 24: 460-467.

19. Molsa M, Tłuczykont M, Markowicz A, Strojek K. Przestrzeganie zaleceń lekarskich (compliance) u chorych na cukrzycę leczonych w opiece ambulatoryjnej. Diabetologia Kliniczna 2012; 1: 213-217.

20. Garber AJ, Duncan TG, Goodman AM et al. Efficacy of metformin in type II diabetes: results of a double-blind, placebo controlled, dose-response trial. Am J Med 1997; 103: 491-497.

21. Howlett H, Davidson J. New prolonged-release metformin improves gastrointestinal tolerability. Br J Diabetes Vasc Dis 2004; 4: 273-277. 